\title{
Snoring in preschool children: prevalence, severity and risk factors
}

\author{
C.E. Kuehni*, M-P.F. Strippoli*, E.S. Chauliac* and M. Silverman\#
}

\author{
ABSTRACT: Epidemiological data on snoring from preschool children are scarce, although \\ habitual snoring (snoring on almost all nights) has been associated with poor long-term \\ outcomes.
}

In a population survey of 6,811 children aged 1-4 yrs (from Leicestershire, UK) the present authors determined prevalence, severity and risk factors for snoring, especially habitual snoring.

In $59.7 \%$ of the children, parents reported snoring in the previous 12 months, including $\mathbf{7 . 9 \%}$ with habitual snoring and $0.9 \%$ with habitual snoring and sleep disturbance. Prevalence of habitual snoring increased with age from $6.6 \%$ in 1 -yr-olds to $13.0 \%$ in 4 -yr-olds. Habitual snoring was associated with: one and both parents smoking (adjusted odds ratio (OR) 1.46 and 2.09, respectively); road traffic (OR 1.23); single parent (OR 1.60); and in White but not South Asian children, socioeconomic deprivation (OR 1.25 and 2.03 for middle and upper thirds of Townsend score, respectively). Respiratory tract symptoms related to atopic disorders and to respiratory infections were strongly associated with snoring; however, body mass index was not.

In conclusion, habitual snoring is common in preschool children with one-third of cases attributable to avoidable risk factors. The strong association with atopic disorders, viral infections and environmental exposures suggests a complex aetiology, based on a general vulnerability of the respiratory tract.

KEYWORDS: Preschool child, prevalence, risk factors, snoring, South Asian, wheeze

noring in children indicates increased upper airway resistance during sleep and is the cardinal symptom of sleepdisordered breathing (SDB) $[1,2]$. The complications of SDB are potentially severe and include neurobehavioural and cardiovascular complications and growth inhibition [1]. Habitual snoring (HS), snoring on almost all nights in so-called primary snorers, has been associated with behavioural problems and poor academic performance even in the absence of intermittent hypoxia, possibly due to increased sleep fragmentation [3-5].

Despite its clinical importance, the epidemiological literature on snoring in childhood is sparse. There are only a few population-based studies, often based on small samples and only rarely including preschool children [6-16]. Published results are heterogeneous with the prevalence of HS ranging $3-12 \%$ and the total prevalence of snoring 21-68\%. Some studies reported an association between HS and male sex [7, 11, 15], being overweight $[12,17,18]$, parental smoking
$[6,13,14]$, breastfeeding [18] and low socioeconomic status $[5,7,19]$, while others did not confirm these findings. Some of these discrepancies might be due to age differences between study populations [20]. An excess of respiratory symptoms related to atopic diseases has been previously reported $[6,7,12,17,18,21]$.

Using a large population-based sample of preschool children, the present authors aimed to: determine prevalence and severity of snoring in preschool children; describe environmental and sociodemographic factors associated with snoring in this age group; and study the association between snoring and other respiratory symptoms. A special focus of the analysis was on HS, the clinically most significant category.

\section{METHODS}

\section{Study design and population}

The Leicestershire Health Authority Child Health Database was used in the study. It includes both the birth notification and perinatal data with mother's self-reported ethnic origin, religion,
AFFILIATIONS

*Institute of Social and Preventive Medicine, University of Bern, Bern, Switzerland.

\# Division of Child Health, Dept of Infection, Immunity and Inflammation, University of Leicester, UK.

\section{CORRESPONDENCE}

C.E. Kuehni

Swiss Paediatric Respiratory

Research Group

Institute of Social and Preventive

Medicine

University of Bern

Finkenhubelweg 11

CH-3012

Bern

Switzerland

Fax: 41316313520

E-mail: kuehni@ispm.unibe.ch

Received:

July 132007

Accepted after revision:

October 312007

SUPPORT STATEMENT

The work presented in this paper was funded by the Swiss National Science Foundation (PROSPER grant 3233069348, 3200-069349, and SNF grant 823B-046481) and the Swiss Society of Paediatrics. Initial data collection was supported by a research grant from Trent NHS Executive (Sheffield, UK; Trent Research Scheme, RBF No. 98XX3).

\section{STATEMENT OF INTEREST}

A statement of interest for this study can be found at

www.erj.ersjournals.com/misc/ statements.shtml 
country of birth and language, to select an age-stratified random sample of White and South Asian (mother selfidentified as Indian, Pakistani, Bangladeshi or other) children aged 1-4 yrs with complete birth records. From this database a random sample of 6,100 White and 2,600 South Asian children (5,400 aged 1 yr and 1,100 in each age group of 2, 3 and 4 yrs) was extracted [22]. The Leicestershire Health Authority Research Ethics Committee (Leicester, UK) approved the study.

\section{Questionnaire}

Parents were sent a single questionnaire including questions on wheeze, cough and upper respiratory symptoms during the past 12 months [23-25]. The questions for 1-yr-olds and their repeatability have been published elsewhere [25]. The questionnaire for 2-5-yr-olds was almost identical and is available from the present authors. The following questions related to snoring. "Over the past 12 months, has your child snored at night? If yes how often, only with a cold/sometimes even without a cold/almost always?" and "Did the snoring disturb your child's sleep, not at all/a little/a moderate amount/a lot?"' $[6,7]$.

The questionnaire also contained sections on diagnoses, healthcare utilisation and treatments for wheeze, environmental exposures, breastfeeding, pets, nursery care, siblings and household members, parental history of atopic diseases, ethnicity and language. Socioeconomic factors were measured at a family level (duration of parental education, number of people per room, single parenthood) and area level (Townsend score, 1991 census data).

Height and weight measurements were available through the Leicestershire Health Authority Child Health Database, assessed in a standardised way by health visitors at birth and at 8, 20, 40 and 60 months. For the analysis, the measurements at birth and those made nearest to the date of the questionnaire were used. The standard deviation score (SDS) for the body mass index (BMI) was calculated from British growth reference curves [26]. International BMI cut-offs were used to define underweight, overweight and obesity in children [27]. The ponderal index (cube root of body mass (kg) divided by height of the children $(\mathrm{cm})$ ) was also calculated.

\section{Statistical analysis}

Based on reported frequency of snoring, children were grouped into four categories: 1) nonsnorers; 2) children snoring only with colds; 3) children snoring also apart from colds; and 4) children snoring almost always. The latter were classified as HS [1, 6, 7]. Descriptive analysis was used to summarise characteristics of the subjects according to snoring category (table 1).

To quantify associations between potential risk factors and different categories of snoring multivariable logistic regression models were used. The main analysis compared HS with nonsnorers. As the present authors hypothesised that the aetiology of HS might differ from the aetiology of less frequent snoring, separate logistic regression models were used to compare the other two snoring categories with nonsnorers.

In addition to age, sex and ethnicity, the following variables were considered for inclusion in the models. 1) Environmental exposures: including maternal smoking during pregnancy (yes/ no), current parental smoking (none, one parent, both parents), electrical cooking (yes/no), central heating (yes/no), reported exposure to road traffic (moderate-to-dense/little-to-none), household pets (cats, dogs, birds or rabbits, guinea pigs etc., all categorised as yes/no), number of siblings, nursery care (yes/ no) and breastfeeding ( $>6$ months). 2) Socioeconomic factors: including the Townsend score, paternal and maternal education (completed full-time education at $\leqslant 16 \mathrm{yrs}$ ), single parenthood, overcrowding $\left(>1\right.$ person $\left.\cdot \mathrm{room}^{-1}\right)$. 3) Clinical features and symptoms: including parental history of atopic disease, upper and lower respiratory symptoms in the child, prevalence and frequency of wheeze, chronic cough, chronic rhinitis, frequency and severity of colds, eczema, birth weight, BMI and ponderal index at the time of the questionnaire. The authors also asked about "posseting" in the first year of life (regurgitation, a common form of gastro-oesophageal reflux in infants).

To explore potential causal pathways, three logistic regression models were developed with increasing complexity. First, a simple model, adjusted only for age, sex and ethnic group (tables 2 and 3; base model). Secondly, a model that was adjusted for all environmental and socioeconomic factors (table 2; partially adjusted model I), and a model that was adjusted for other clinical and biological features (table 3 ; partially adjusted model II). Thirdly, a model adjusting for environmental, social and clinical conditions simultaneously (tables 2 and 3; fully adjusted model). All variables associated with prevalence of HS $(\mathrm{p}<0.05)$ in one model were included in the next modelling step, except when the information contained in two or more variables was so similar (co-linear) that only one could be taken into the next modelling step. This was, for instance, the case for paternal and maternal education, current maternal smoking and smoking during pregnancy, and Townsend score and household size (crowding). Results are presented as odds ratios (OR) with $95 \%$ confidence intervals (CI). Based on literature and previous findings [28], the current authors hypothesised that risk factors might differ between ethnic groups (South Asians/Whites), between young males and young females, and between age groups (1-yr-olds/2-5yr-olds). Therefore, stratified analyses were performed and evidence for heterogeneity between groups was tested for using interaction terms. Because South Asian children and 1yr-olds had been over-sampled weighted, analyses were also performed, which accounted for the sampling scheme. As the results were similar to the main analysis, unweighted results are reported for simplicity.

The population-attributable risk fraction, or proportion of HS that could be prevented if the associations were causal and the risk factors were eliminated completely from the population, was calculated from the logistic regression framework by using the aflogit command in STATA [29], which allows confounders to be taken into account.

\section{RESULTS}

The overall response rate was $80 \%(6,811$ out of the 8,500 families with a valid address), and was higher in White $(4,986$ $(84 \%))$ than in South Asian (1,825 (72\%)) families, corresponding to 16 and $29 \%$ of White and South Asian children aged 15 yrs living in Leicestershire (UK) at the time. In total, 69 (1\%) 


\begin{tabular}{|c|c|c|c|c|c|c|c|c|}
\hline \multirow[b]{3}{*}{ Total } & \multicolumn{8}{|c|}{ Reported frequency of snoring } \\
\hline & \multicolumn{2}{|c|}{ Never } & \multicolumn{2}{|c|}{ Only with colds } & \multicolumn{2}{|c|}{ Sometimes without colds } & \multicolumn{2}{|c|}{ Almost always } \\
\hline & $2714(40.3)$ & $39.1-41.4$ & $1862(27.6)$ & $26.6-28.7$ & $1635(24.2)$ & $23.2-25.3$ & $531(7.9)$ & $7.2-8.5$ \\
\hline 2 & $319(39.5)$ & $36.1-42.9$ & $225(27.9)$ & $24.7-30.9$ & $208(25.7)$ & $22.7-28.8$ & $56(6.9)$ & $5.2-8.7$ \\
\hline 3 & $331(38.5)$ & $35.2-41.7$ & $198(23.0)$ & $20.2-25.8$ & $245(28.5)$ & $25.5-31.5$ & $86(10.0)$ & $8.0-12.0$ \\
\hline 4 & $345(39.8)$ & $36.5-43.1$ & $180(20.8)$ & $18.1-23.5$ & $229(26.4)$ & $23.5-29.3$ & $113(13.0)$ & $10.8-15.3$ \\
\hline \multicolumn{9}{|l|}{ Sex } \\
\hline Female & $1387(43.0)$ & $41.3-44.7$ & 897 (27.8) & $26.3-29.4$ & 708 (22.0) & $20.5-23.4$ & $234(7.3)$ & $6.4-8.1$ \\
\hline \multicolumn{9}{|l|}{ Parental smoking } \\
\hline None & $1878(43.0)$ & $41.5-44.5$ & $1209(27.7)$ & $26.4-29.0$ & $990(22.7)$ & 21.4-23.9 & $290(6.6)$ & $5.9-7.4$ \\
\hline One parent & $621(36.3)$ & $34.0-38.6$ & $471(27.5)$ & $25.4-29.6$ & $461(26.9)$ & $24.8-29.0$ & $158(9.2)$ & $7.9-10.6$ \\
\hline Both parents & $215(32.4)$ & $28.8-35.9$ & $182(27.4)$ & $24.0-30.8$ & $184(27.7)$ & $24.3-31.1$ & $83(12.5)$ & $10.0-15.0$ \\
\hline \multicolumn{9}{|l|}{ Townsend score } \\
\hline Low deprivation & $1020(41.4)$ & $39.4-43.3$ & 715 (29.0) & $27.2-30.8$ & $572(23.2)$ & 21.5-24.9 & $159(6.5)$ & $5.5-7.4$ \\
\hline $\begin{array}{l}\text { Medium depri- } \\
\text { vation }\end{array}$ & 894 (39.5) & $37.5-41.5$ & 647 (28.6) & $26.7-30.5$ & $546(24.1)$ & $22.4-25.9$ & $175(7.7)$ & $6.6-8.8$ \\
\hline High deprivation & $750(39.5)$ & $37.3-41.7$ & $469(24.7)$ & $22.8-26.7$ & $487(25.7)$ & 23.7-27.6) & $191(10.1)$ & $8.7-11.4$ \\
\hline
\end{tabular}

children with missing information on frequency of snoring were excluded from further analyses, leaving 6,742 children.

\section{Prevalence and severity of all categories of snoring}

In total, parents of 4,028 (59.7\%) children reported that their child had snored in the previous 12 months; including 1,862 $(27.6 \%)$ children snoring only with colds, 1,635 (24.2\%) snoring sometimes apart from colds, and 531 (7.9\%) snoring almost always (HS). HS was more common in young males, White children and 2-4-yr-olds compared with younger children (table 1; online supplementary tables E1A and E1B). This was similar for snoring sometimes without colds, while snoring only with colds was reported more often for younger children, with no sex difference. For 44 children, an operation to remove adenoids and/or tonsils was reported (none of the 1-yr-olds, and $4(0.5 \%), 13(1.5 \%)$ and $27(3.0 \%)$ of children aged 2,3 and 4 yrs, respectively). Moderate or severe sleep disturbance due to snoring was reported most often for HS (60 (11.3\%) out of 530 of all HS), while mild sleep disturbance was reported more often for children snoring only with colds (fig. 1). In total, parents of $60(0.9 \%)$ children reported HS with moderate or severe sleep disturbance. Otitis media in the past 12 months was reported by $34.6 \%$ of nonsnorers, $42.2 \%$ of children snoring only with colds, $48.1 \%$ of children snoring sometimes without colds and $52.5 \%$ of HS $(\mathrm{p}<0.001)$. For recurrent otitis media, these figures were 13.4, 17.0, 21.3 and $27.3 \%$, respectively $(\mathrm{p}<0.001)$.

\section{Association between HS and environmental and socioeconomic factors}

Adjusting only for age, sex and ethnic group (base model), HS was reported more often in children exposed to air pollutants (environmental tobacco smoke, reported road traffic, absence of central heating and of electric cooking; table 2). In the fully adjusted model, only the effect of parental smoking remained significant with OR for HS of 1.43 if one and 2.06 if both parents smoked. The association was stronger in 1-yr-olds than in older children (OR 2.10 and 3.14 in 1-yr-olds, and 1.22 and 1.47 in 2-4-yr-olds for one and two smokers respectively; $\mathrm{p}$ for interaction $=0.010)$. Maternal smoking during pregnancy was also strongly associated with HS (OR (95\% CI) in base model 2.10 (1.66-2.67); $\mathrm{p}<0.001)$. As the same females smoked during pregnancy and at the time of the survey, it was not possible to distinguish the effects of pre-natal and current smoke exposure, and only one variable chosen for current smoking could be included in the adjusted models. A longer duration of breastfeeding was associated with a lower prevalence of snoring (OR in base model: $0.73(0.57-0.95)$ ), but the association disappeared after adjustment for parental smoking and was not age dependent.

HS was reported more often for children from disadvantaged families, with a single parent, overcrowded households or low paternal or maternal education. The area-based deprivation measure (Townsend score) was associated with HS in White, but not in South Asian preschool children ( $\mathrm{p}$ for 
TABLE 2 Environmental and socioeconomic factors associated with habitual snoring in the previous 12 months ${ }^{\#}$

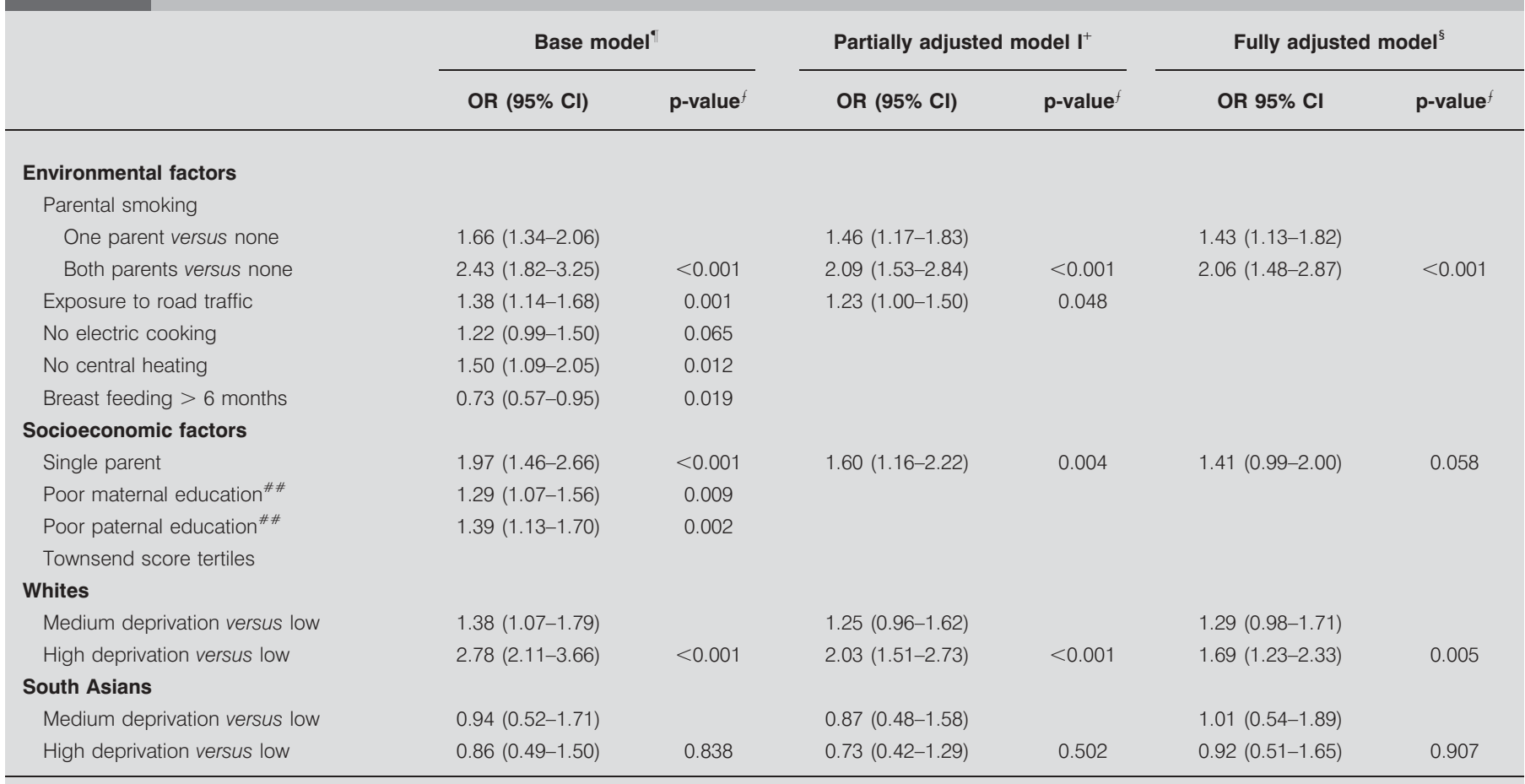

OR: odds ratio; $\mathrm{Cl}$ : confidence interval. ${ }^{\#}: \mathrm{n}=3,245 ;{ }^{\circ}$ : adjusted for age, sex and ethnic group; ${ }^{+}$: adjusted for age, sex, ethnic group and all environmental and socioeconomic factors; ${ }^{\text {s. }}$ adjusted for age, sex, ethnic group and all environmental and socioeconomic factors and clinical features simultaneously; ${ }^{f}$ : refer to Wald test

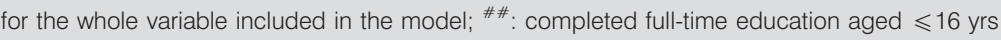

interaction <0.001). Adjusting simultaneously for environmental exposures and socioeconomic factors, parental smoking, traffic exposure, single parenthood and Townsend score in whites remained independent predictors of HS (table 2; partially adjusted model I). When adjusting additionally for clinical features (table 2; fully adjusted model) the strength of the association (OR) between snoring and environmental exposures decreased, but did not disappear. When children with current wheeze or asthma were excluded from the analysis, the associations with environmental factors were similar to the model including all children (data not shown).

Using a statistical approach that allowed multiple risk factors to be taken into account [29], a total of $33.4 \%$ of HS could be attributed to air pollutants (20\% to parental smoking, $15 \%$ to exposure to road traffic and $3 \%$ to lack of central heating).

These analyses were repeated for the less severe categories of snoring. Snoring sometimes without colds was associated, although less strongly, with the same environmental exposures as HS (online supplementary table E2A). Snoring only with colds was only weakly associated with current parental smoking and reported road traffic, but not with the other exposures (online supplementary table E2B).

\section{Association between HS and clinical and biological features}

Habitual snoring was strongly associated with a large number of clinical conditions. This included conditions potentially related to atopy, such as maternal history of asthma and a personal history of wheeze, eczema, chronic night cough and chronic rhinitis. However, snoring was also independently associated with symptoms related to viral infection, such as frequency of colds and otitis media, and with posseting (regurgitation) in the first year of life (table 3; base model and partially adjusted model II). These associations remained essentially unchanged after additional adjustment for environmental exposures and socioeconomic factors, suggesting that they were not explained by confounding with exposures, such as parental smoking, that increase the risk for both snoring and other respiratory conditions (table 3; fully adjusted model).

BMI was not associated with HS, either when analysed as a continuous variable (OR 1.03 (95\% CI 0.95-1.12); by SDS $\mathrm{p}=0.42$ ) or as a categorical variable [27] (table 3; base model). Similarly, no association was found between HS and ponderal index at the time of the study $(p=0.46$ when analysed as a continuous variable, $\mathrm{p}=0.57$ when analysed as tertiles), or birth weight $(p=0.93$ and $p=0.88$, respectively, when analysed as a continuous or categorical variable).

These analyses were repeated comparing the milder categories of snorers with nonsnorers. For children snoring sometimes apart form colds (online supplementary table E3A) the results were very similar to those with HS. For children snoring only with colds (online supplementary table E3B) the associations with other respiratory symptoms and posseting were similar to those for more severe snoring, while the association with atopic disorders was less consistent. 
TABLE 3 Clinical and biological features associated with habitual snoring in the previous 12 months ${ }^{\#}$

\begin{tabular}{|c|c|c|c|c|c|c|}
\hline & OR $(95 \% \mathrm{Cl})$ & $p$-value ${ }^{\S}$ & OR $(95 \% \mathrm{Cl})$ & p-value ${ }^{\S}$ & OR $(95 \% \mathrm{Cl})$ & p-value \\
\hline \multicolumn{7}{|l|}{ Demographic variables } \\
\hline Male sex & $1.33(1.10-1.61)$ & 0.003 & $1.25(1.02-1.52)$ & 0.033 & $1.27(1.03-1.55)$ & 0.025 \\
\hline Age $\geqslant 2$ yrs & $1.74(1.43-2.10)$ & $<0.001$ & $1.94(1.57-2.40)$ & $<0.001$ & $2.01(1.62-2.49)$ & $<0.001$ \\
\hline Attacks of wheeze $1-10$ versus none & $2.52(2.04-3.11)$ & & $1.48(1.17-1.87)$ & & $1.36(1.07-1.73)$ & \\
\hline Attacks of wheeze $>10$ versus none & $9.70(5.80-16.16)$ & $<0.001$ & $3.27(1.85-5.79)$ & $<0.001$ & $2.61(1.45-4.70)$ & 0.001 \\
\hline Eczema ever & $1.67(1.38-2.02)$ & $<0.001$ & $1.20(0.98-1.48)$ & 0.082 & $1.25(1.01-1.54)$ & 0.039 \\
\hline Maternal history of wheeze or asthma & $1.99(1.59-2.49)$ & $<0.001$ & $1.37(1.07-1.75)$ & 0.012 & $1.33(1.03-1.71)$ & 0.027 \\
\hline \multicolumn{7}{|l|}{ Other respiratory symptoms } \\
\hline Cough at night & $3.32(2.72-4.05)$ & $<0.001$ & $1.85(1.48-2.31)$ & $<0.001$ & $1.79(1.43-2.26)$ & $<0.001$ \\
\hline Otitis media" 1 episode versus none & $1.60(1.27-2.02)$ & & $1.38(1.08-1.76)$ & & $1.42(1.10-1.82)$ & \\
\hline Otitis media $>1$ episode versus none & $2.70(2.14-3.43)$ & $<0.001$ & $1.65(1.27-2.14)$ & $<0.001$ & $1.69(1.29-2.20)$ & $<0.001$ \\
\hline \multicolumn{7}{|l|}{ Body mass index } \\
\hline Underweight versus normal & $0.86(0.51-1.44)$ & & & & & \\
\hline Overweight versus normal & $1.16(0.88-1.52)$ & & & & & \\
\hline Obese versus normal & $1.03(0.64-1.68)$ & 0.663 & & & & \\
\hline \multicolumn{7}{|l|}{ Posseting $^{+}$during first year of life } \\
\hline A little versus none & $1.72(1.36-2.19)$ & & $1.43(1.11-1.85)$ & & $1.43(1.11-1.85)$ & \\
\hline A lot versus none & $2.80(2.08-3.77)$ & $<0.001$ & $1.68(1.22-2.32)$ & 0.003 & $1.65(1.19-2.30)$ & 0.005 \\
\hline
\end{tabular}

OR: odds ratio; $\mathrm{Cl}$ : confidence interval. ${ }^{*}: \mathrm{n}=3,245$; ${ }^{\bullet}$ : adjusted for age, sex and ethnic group; ${ }^{+}$: adjusted for age, sex, ethnic group and all environmental and

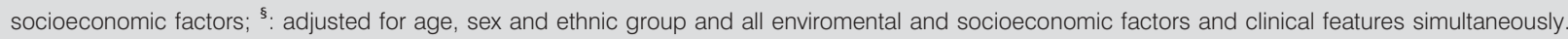

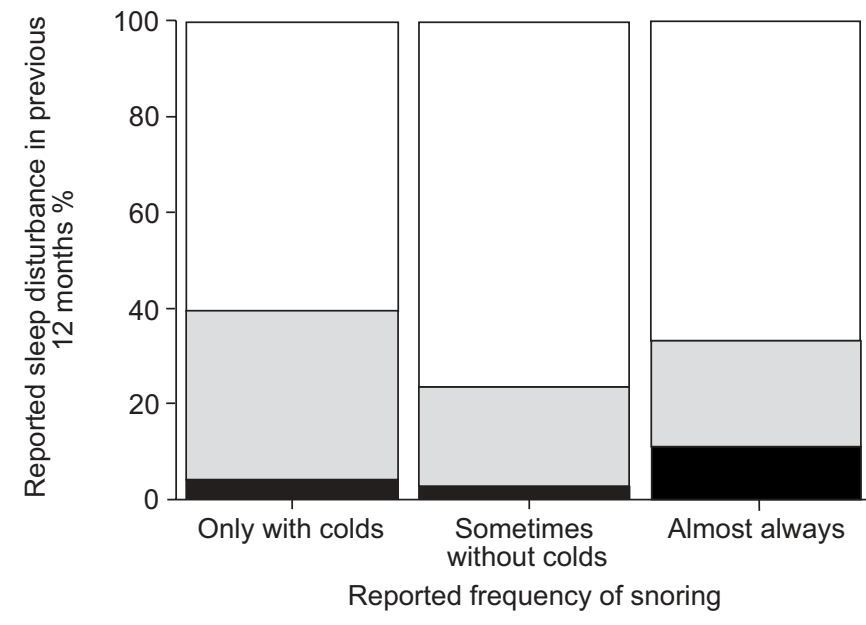

FIGURE 1. Prevalence of reported sleep disturbance associated with snoring in the previous 12 months by frequency of snoring. The number of subjects in each category were as follows: only with colds, $n=1,851$; sometimes without colds, $\mathrm{n}=1,633$; almost always, $\mathrm{n}=530$. $\square$ : no reported sleep disturbance; $\square$ : mild reported sleep disturbance; $\mathbf{\square}$ : moderate/severe reported sleep disturbance. The reason for discrepancy between the number of subjects compared with table 3 is due to the fact that 14 children did not respond to the question on sleep disturbance.

\section{Sensitivity analyses}

The associations with environmental exposures and clinical features were similar for young females and young males, and for White and South Asian children (all p-values for interaction terms $>0.01$ ) Similarly, a weighted analysis adjusting for over sampling of young children and those of South Asian origin gave similar results to the main analysis.

\section{DISCUSSION}

In this large representative survey, $60 \%$ of preschool children were reported to have snored in the previous year, $8 \%$ were HSs and $11 \%$ of these (almost $1 \%$ of the cohort) were HSs with significant sleep disturbance, a group at risk of long-term neurobehavioural problems [3-5]. Assuming a causal association, approximately one-third of cases with HS might be attributable to avoidable environmental exposures (parental smoking and traffic exposure). Snoring was associated both with clinical features of atopic disease and with symptoms caused by viral infections.

\section{Methodological issues}

This cross-sectional survey is the largest community-based study of snoring in children $<5$ yrs of age and the only one covering the age range 1-4 yrs. Most other publications focused on 3-5-yr-olds and included only a few hundred subjects [9-12]. The present authors studied a community-based sample of 


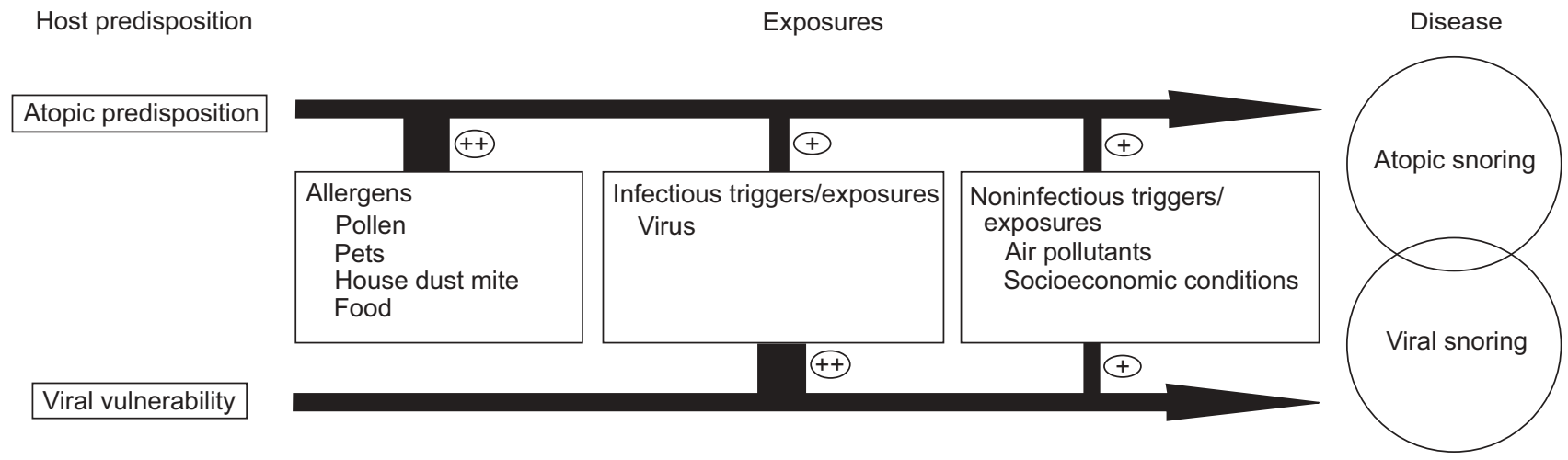

FIGURE 2. Schematic illustration of the suggested causal pathways which lead to chronic snoring in young children. ++: high contribution; +: moderate contribution.

children, had a good response rate and included South Asians, the largest ethnic minority group in the UK. Therefore, the results should be representative of UK toddlers. A large number of environmental exposures, socioeconomic factors and clinical features were assessed.

A limitation shared with other community-based surveys is the lack of objective outcomes. In this cohort, the present authors assessed whether the families understood the different respiratory symptoms listed in the questionnaire and, although it was found that some parents confused wheeze with rattly breathing or cough, snoring was clearly distinguished both by White and South Asian parents [24]. Moreover, a recent study showed that parental reports of frequent snoring were highly sensitive and specific when compared with overnight polysomnography [2]. Although the latter remains the "gold standard" for the diagnosis of obstructive sleep apnoea syndrome and SDB [1] it is clearly impractical for a large population survey, as are methods such as overnight pulse oximetry, audio and videotaping. Several recent studies have shown strong associations between reported habitual snoring in children and adults and adverse behavioural and academic outcomes, even in the absence of intermittent hypoxia $[1,4,5$, 30]. This may be due to increased sleep fragmentation. Considering all this, the current authors believe that parentreported HS can be used as a simple indicator of clinically relevant disease.

\section{Prevalence of snoring in preschool children}

As assessment of snoring by questionnaire has not been standardised, differences in reported prevalence between studies are unavoidable. In common with other surveys $[6,7]$ a question on snoring frequency in the past 12 months was used, with the answer categories: never; only with colds; sometimes apart from colds; and almost always. Other studies asked if snoring occurred "never", "rarely", "frequently" or "always", without differentiating between snoring with or without colds. In spite of the differences in wording, the prevalence of HS in the current study (7\% in 1-yr-olds, increasing to $13 \%$ in 4 -yr-olds) was comparable to data from $4-5$-yr-olds in the UK (12\%) [10], from 2-5-yr-olds in Australia $(11 \%)$ [12], and from schoolchildren $(5-10 \%)[6,7,9,31]$. The total prevalence of snoring in the current sample $(60 \%)$ was similar to data from preschool children (70\%) [10] and schoolchildren (35-64\%) $[6,7,9,31]$. An increasing prevalence of HS from 1-4-yr-olds has not previously been reported and might be due to age-dependent increments in adenoid size, which peak at 7-10 yrs of age [32]. In adults, the prevalence of HS is higher in males. For children, published data are less consistent, with some studies reporting a sex difference $[7,14$ $16,18]$ and others none $[6,8,11]$. The present authors found a slightly higher prevalence in young males (OR 1.33).

Studies from the USA report an increased prevalence in African-Americans compared with Whites [17, 19]. In the current study, South Asian children, the largest ethnic minority group in the UK, had a lower crude prevalence. This difference remained after adjusting for other clinical conditions, (table 3; partially adjusted model II) but disappeared after adjustment for differences in parental smoking and socioeconomic factors (table 3; fully adjusted model). This suggests that the differences in prevalence between ethnic groups might be caused by differences in environmental exposures rather than biological factors.

\section{Association with environmental exposures and socioeconomic factors}

An association between snoring and passive smoking has been demonstrated for adults [33] and children [7, 18], sometimes disappearing after adjustment for social class [17]. The current authors confirmed a strong and dose-dependent effect of parental smoking (both versus one smoking parent) on frequency of snoring even after adjustment for socioeconomic factors. This dose-response relationship and the fact that the association was stronger in younger children who spend more time at home and who might be more vulnerable support a causal association. The present analysis suggests that approximately one in five cases of HS could be avoided if parents did not smoke. Because of the close correlation between pre-natal and post-natal smoke exposures it was not possible to distinguish their effects.

HS was also more common in households that had no central heating, used gas for cooking and were exposed to greater road traffic. These are new findings. Although the authors found that some of these effects disappeared after adjustment for the Townsend score, this might be an over-adjustment because area-based deprivation scores are closely associated with housing conditions and air pollution. The increased prevalence 
of snoring in children from disadvantaged families was only partially explained by a higher exposure to parental smoking and air pollutants. Other unmeasured lifestyle variables, such as nutrition, must also play a role.

\section{Association with clinical features}

A strong association was found between snoring and other upper and lower respiratory symptoms. This was not only the case for symptoms associated with atopy (wheeze, eczema, maternal asthma), which has been reported by others $[6,12,18$, 34], but also for symptoms that are usually associated with infection (frequent colds, otitis media).

Therefore, it was hypothesised that, as in other airway disorders, snoring might result from an interaction between underlying host predisposition, various intrinsic mechanisms and external triggers, which together lead to a similar endpoint. The present authors propose a tentative model (fig. 2), which will be revised as further evidence accumulates. Chronic snoring in children might arise via several inflammatory pathways which independently affect upper airway resistance or compliance. For some mechanisms, such as atopy, there is a simple explanation for the association between upper and lower airway vulnerability. Increased susceptibility to viral respiratory infection may be another. A hypothetical mechanism for such susceptibility has been proposed [35]. GOLDBART et al. [35] provide evidence that early exposure to respiratory syncytial virus might induce neuro-immunomodulatory changes within adenotonsillar tissue, predisposing to an accelerated proliferative response and, hence, enlargement when exposed to other stimuli such as viruses or allergens.

An association between HS and gastro-oesophageal reflux has been reported for adults [36]. For children, an association with posseting is a new finding. This physiological form of gastrooesophageal reflux is largely confined to the first year of life, and cannot therefore be directly related to snoring later in childhood. However, it may be speculated that intermittent contact with gastric juices leads to chronic pharyngeal inflammation, possibly predisposing to snoring by altered compliance or calibre of the upper airways.

No association was found between snoring and overweight or obesity, whether assessed by BMI or ponderal index. This is unlikely to be due to lack of statistical power. However, there are data suggesting that the association between obesity and snoring might change with age [20] and that BMI might play a minor role in the aetiology of snoring in preschool children, in contrast to adolescence and adulthood [12, 17, 18]. In young children, with relatively noncollapsible upper airways, obesity per se might not elicit the noise of snoring.

\section{Conclusions}

In total, it was found that $60 \%$ of preschool children had snored during the past 12 months, with $8 \%$ snoring habitually and nearly $1 \%$ reporting habitual snoring with sleep disturbance, the latter representing children at risk of adverse consequences. Risk factors for habitual snoring in this age group were exposure to parental smoking, other air pollutants and socioeconomic deprivation, but not overweight. The strong association with a number of other upper and lower respiratory symptoms, both those associated with atopy and those associated with viral infection, suggests common pathways, such as increased host susceptibility in the respiratory tract.

\section{ACKNOWLEDGEMENTS}

The authors would like to acknowledge the work of S.R. Leiva de la Ros, who contributed significantly to the literature search, data analysis and writing of earlier versions of this manuscript, and would have been second author. Because we were unable to trace her address at the time of submission she could not be officially credited as an author. The authors would like to thank the parents of all the Leicestershire children who were involved for completing the questionnaires, and T. Davis (Specialist Community, Child Health Services, Leicester City West Primary Care Trust, Leicester, UK) for assistance with the Leicestershire Child Health Database.

\section{REFERENCES}

1 Schechter MS. Technical report: diagnosis and management of childhood obstructive sleep apnoea syndrome. Paediatrics 2002; 109: e69.

2 Montgomery-Downs HE, O'Brien LM, Holbrook CR, Gozal D. Snoring and sleep-disordered breathing in young children: subjective and objective correlates. Sleep 2004; 27: 87-94.

3 O'Brien LM, Mervis CB, Holbrook CR, et al. Neurobehavioural implications of habitual snoring in children. Paediatrics 2004; 114: 44-49.

4 Urschitz MS, Eitner S, Guenther A, et al. Habitual snoring, intermittent hypoxia, and impaired behaviour in primary school children. Paediatrics 2004; 114: 1041-1048.

5 Urschitz MS, Guenther A, Eggebrecht E, et al. Snoring, intermittent hypoxia and academic performance in primary school children. Am J Respir Crit Care Med 2003; 168: 464-468.

6 Corbo GM, Fuciarelli F, Foresi A, De Benedetto F. Snoring in children: association with respiratory symptoms and passive smoking. BMJ 1989; 299: 1491-1494.

7 Corbo GM, Forastiere F, Agabiti N, et al. Snoring in 9- to 15-year-old children: risk factors and clinical relevance. Paediatrics 2001; 108: 1149-1154.

8 Ferreira AM, Clemente V, Gozal D, et al. Snoring in Portuguese primary school children. Paediatrics 2000; 106: e64.

9 Gottlieb DJ, Vezina RM, Chase C, et al. Symptoms of sleepdisordered breathing in 5-year-old children are associated with sleepiness and problem behaviours. Paediatrics 2003; 112: 870-877.

10 Ali NJ, Pitson DJ, Stradling JR. Snoring, sleep disturbance, and behaviour in 4-5 year olds. Arch Dis Child 1993; 68: 360-366.

11 Castronovo V, Zucconi M, Nosetti L, et al. Prevalence of habitual snoring and sleep-disordered breathing in preschool-aged children in an Italian community. J Pediatr 2003; 142: 377-382.

$12 \mathrm{Lu} \mathrm{LR}$, Peat JK, Sullivan CE. Snoring in preschool children: prevalence and association with nocturnal cough and asthma. Chest 2003; 124: 587-593.

13 Owen GO, Canter RJ, Robinson A. Snoring, apnoea and ENT symptoms in the paediatric community. Clin Otolaryngol Allied Sci 1996; 21: 130-134. 
14 Brunetti L, Rana S, Lospalluti ML, et al. Prevalence of obstructive sleep apnoea syndrome in a cohort of 1,207 children of southern Italy. Chest 2001; 120: 1930-1935.

15 Kaditis AG, Finder J, Alexopoulos EI, et al. Sleepdisordered breathing in 3,680 Greek children. Pediatr Pulmonol 2004; 37: 499-509.

16 Mitchell EA, Thompson JM. Snoring in the first year of life. Acta Paediatr 2003; 92: 425-429.

17 Redline S, Tishler PV, Schluchter M, Aylor J, Clark K, Graham G. Risk factors for sleep-disordered breathing in children. Associations with obesity, race, and respiratory problems. Am J Respir Crit Care Med 1999; 159: 1527-1532.

18 Chng SY, Goh DY, Wang XS, Tan TN, Ong NB. Snoring and atopic disease: a strong association. Pediatr Pulmonol 2004; 38: 210-216.

19 Montgomery-Downs HE, Jones VF, Molfese VJ, Gozal D. Snoring in preschoolers: associations with sleepiness, ethnicity, and learning. Clin Pediatr (Phila) 2003; 42: 719-726.

20 Kaditis AG, Alexopoulos EI, Hatzi F, et al. Adiposity in relation to age as predictor of severity of sleep apnoea in children with snoring. Sleep Breath 2007; [Epub ahead of print PMID: 17684780].

21 Gozal D, Pope DW Jr. Snoring during early childhood and academic performance at ages thirteen to fourteen years. Paediatrics 2001; 107: 1394-1399.

22 Kuehni CE, Brooke AM, Strippoli M-PF, Spycher BD, Davis A, Silverman M. Cohort profile: the Leicester respiratory cohorts. Int J Epidemiol 2007; 36: 977-985.

23 Kuehni CE, Davis A, Brooke AM, Silverman M. Are all wheezing disorders in very young (preschool) children increasing in prevalence? Lancet 2001; 357: 1821-1825.

24 Michel G, Silverman M, Strippoli M-PF, et al. Parental understanding of "wheeze" and its impact on asthma estimates. Eur Respir J 2006; 28: 1124-1130.

25 Strippoli M-PF, Silverman M, Michel G, Kuehni CE. A parent-completed respiratory questionnaire for one-year olds: repeatability. Arch Dis Child 2007; 92: 861-865.

26 Cole TJ, Freeman JV, Preece MA. British 1990 growth reference centiles for weight, height, body mass index and head circumference fitted by maximum penalized likelihood. Stat Med 1998; 17: 407-429.

27 Cole TJ, Flegal KM, Nicholls D, Jackson AA. Body mass index cut offs to define thinness in children and adolescents: international survey. BMJ 2007; 335: 194.

28 Kuehni CE, Strippoli M-PF, Low N, Brooke AM, Silverman M. Wheeze and asthma prevalence and related health-service use in white and south Asian pre-school children in the United Kingdom. Clin Exp Allergy 2007; 37: 1738-1746.

29 Brady AR. sbe21-Adjusted population attributable fractions from logistic regressions. STB Reprints 1998; 7: 137-143.

30 Gottlieb DJ, Yao Q, Redline S, Ali T, Mahowald MW. Does snoring predict sleepiness independently of apnoea and hypopnoea frequency? Am J Respir Crit Care Med 2000; 162: 1512-1517.

31 Schlaud M, Urschitz MS, Urschitz-Duprat PM, Poets CF. The German study on sleep-disordered breathing in primary school children: epidemiological approach, representativeness of study sample, and preliminary screening results. Paediatr Perinat Epidemiol 2004; 18: 431-440.

32 Vogler RC, Ii FJ, Pilgram TK. Age-specific size of the normal adenoid pad on magnetic resonance imaging. Clin Otolaryngol 2000; 25: 392-395.

33 Franklin KA, Gislason T, Omenaas E, et al. The influence of active and passive smoking on habitual snoring. Am J Respir Crit Care Med 2004; 170: 799-803.

34 Sulit LG, Storfer-Isser A, Rosen CL, Kirchner HL, Redline S. Associations of obesity, sleep-disordered breathing, and wheezing in children. Am J Respir Crit Care Med 2005; 171: 659-664.

35 Goldbart AD, Mager E, Veling MC, et al. Neurotrophins and tonsillar hypertrophy in children with obstructive sleep apnoea. Pediatr Res 2007; 62: 489-494.

36 Janson C, Gislason T, De Backer W, et al. Daytime sleepiness, snoring and gastro-oesophageal reflux amongst young adults in three European countries. I Intern Med 1995; 237: 277-285. 